\title{
Epidemiologic Correlates of Chronic Respiratory Infections in Adults an Urban Slum of Bhubaneswar, Odisha, India
}

\author{
Sonali $\operatorname{Kar}^{1}$, Ipsa Mohapatra ${ }^{1} \&$ Amrita Konar ${ }^{1}$ \\ ${ }^{1}$ Kalinga Institute of Medical Sciences, Bhubaneswar, Odisha, India \\ Correspondence: Dr. Sonali Kar, Associate Professor, Community Medicine, Kalinga Institute of Medical \\ Sciences, Bhubaneswar, Odisha, India. Tel: 91-943-842-3273. E-mail: sonsam72@yahoo.co.uk
}

Received: June 5, 2016 Accepted: July 14, 2016 Online Published: August 5, 2016

doi:10.5539/gjhs.v9n4p64 URL: http://dx.doi.org/10.5539/gjhs.v9n4p64

\begin{abstract}
Introduction: Urbanization is marked by emergence of slum areas, wherein migrants from the nearby villages stay in temporary establishments for seeking avenues of employment. These dwellings lack most of the essential living conditions like safe water, healthy living conditions and access to health services. This population is also vulnerable to social evils like alcohol and tobacco addiction. KIMS, a medical college in Bhubaneswar, Odisha, India has an Urban Health Training Centre (UHTC) that caters to a slum population of nearly 12,000 population for their primary health needs. Out of the monthly average of 200 patients /day, it is observed that respiratory symptoms complaints were highest both among the young and adults. Hence the study was conceived with the following objectives.
\end{abstract}

Aims \& Objectives: To assess the cumulative prevalence of Chronic Respiratory Infections and prevalence of specific respiratory symptoms in urban slum population along with a gender break up.

To assess the association between the living conditions, tobacco use with the respiratory manifestations if any.

Methodology: A house to house survey was done wherein all population aged 20-64years were interviewed using a pretested predesigned questionnaire adapted from questionnaire used in International Union Against Tuberculosis and Lung Diseases (IUATLD) study. Given the prevalence of nearly 4\%, with 95\% CI and a relative error of $20 \%$, the optimum sample is considered to be nearly 400 . For the study Chronic Respiratory Infections (CRI) was defined as reporting of 3 or more episodes of some specific common respiratory symptoms in last one year or a diagnosed case of asthma/COPD, warranting medical treatment.

Results: The cumulative prevalence for CRI was seen as $11.7 \%$, dry cough being the most common complaint ie $23.25 \%$ in both sexes. Smoking (both men and women), overcrowding and history of TB were seen as positive predictors of the disease. Use of wood or kerosene in case of women gave an OR of 6.1 times for manifestation of the disease.

Conclusion: Chronic Respiratory Illness is a major burden for slum dwellers and they should be educated against the risk factors and take appropriate precautions to safeguard against the illness.

Keywords: chronic respiratory infections, slums, overcrowding, tobacco use

\section{Introduction}

Urban slums are a common feature in cities of almost all low middle income countries like India and are an extremely vulnerable population with restricted access to health facilities. The adverse living conditions of these populations make them a major reservoir for a wide spectrum of health conditions that the formal health sector must deal with subsequently and perhaps are not ready for the same. Slum dwellings usually come up near an established industrial or rapidly developing area, mainly comprising of migrant poor populations from neighbouring villages or states in search of employment. The existing health sector becomes aware of the health problems of these slum populations relatively late in the course of their illnesses. The services are often not strategized for slums dwellers in terms of cost and affordability and thus the formal health sector inevitably deals with the severe and end-stage complications of these diseases, at a substantially greater cost than what it costs to manage non-slum community populations. The results thereof too are often dismal. The unpredictable nature of slum settlements, and uniqueness of their social, cultural and exposures behaviours, limits our knowledge on the spectrum, burden, and determinants of illnesses in these communities that give rise to these complications, 
especially of those diseases that are chronic but preventable. In affirmation to the United Nations Millennium Declaration of 2000, to tackle the challenge of setting specific goals of achieving "significant improvement in the lives of at least 100 million slum dwellers by the year 2020" (UN Declaration, 2000), preparative action needs to be taken. Today, nearly 1 billion people, or $32 \%$ of the world's urban population are estimated to live in slums. In 30 years, this population is projected to increase to about 2 billion (United Nations Human Settlements Programme, 2003; Sclar, Garau, \& Carolini, 2005).

Odisha is one of the 29 states in India and its capital Bhubaneswar, like most cities in India is now facing a rapid demographic transition. The capital city of Odisha, Bhubaneswar, has remained no exception to emergence of slums. As per a study on slum population by the Bhubaneswar Development Authority (BDA), considerable population amounting to $2,00,097$, i.e. $30 \%$ of the city's total population is living in slums. The settlements in the city can be classified into slum colonies belonging to industrial workers, common slums, population squatting on the land belonging to Indian railways and other govt. agencies. Astute lack of civic services, unhygienic living conditions compounded with increase in housing stock deficit gave raise to slum dwellings and its health problems (http://www.odisha.gov.in/forest_environment).

Kalinga Institute of Medical Sciences, a premier medical college in Bhubaneswar has an Urban Health Training Centre (UHTC) that caters primary health care to slums in close proximity of four kilometres with a population of nearly 12,000 . The current study was conceived in retrospection to the large number of adults presenting to the daily outdoor care clinic with diverse respiratory complaints.

\subsection{Aims \& Objectives}

1) To assess the cumulative/mean prevalence of Chronic Respiratory Infections and prevalence of specific respiratory symptoms in urban slum population with a gender wise break up.

2) To assess the association between the living conditions, tobacco use with the respiratory manifestations if any.

\section{Materials and Methods}

A cross sectional study was planned between June 2015 to November 2015 after seeking the Institutional Ethical clearance for the study. The study was done in the slums under the UHTC, KIMS among the adult population.

Operational definition for Chronic Respiratory Infections (CRI) for the purpose of the study was a recent past complaint of respiratory system recurring at least three times in the last year. The subjects were asked for recurrence of identified specific respiratory symptoms like, dry cough, cough with sputum, shortness of breath (SOB) and wheezing or asthmatic attacks along with any history of Tuberculosis. The study is purely symptoms based, as reported by the subjects and there was no scope of performing any medical tests like chest X-ray (CXR) or spirometry due to financial restraints. Current symptoms were assessed by a respiratory system examination for breath sounds or added sounds.

The Inclusion criterion was set at any individual 20-64 years of age, irrespective of gender and willing to participate in the study. Diagnosed cases of Chronic Obstructive or Respiratory diseases were also included in the study as the recurrence of symptoms in their case in the last year could be taken as exacerbations of the respiratory illness and would be hinting at uncontrolled disease exacerbated due to certain living conditions. Only those not willing to participate, or very sick at the time of visit, pregnant women \& mentally incapacitated were excluded from the study. This being an epidemiological study, we excluded the very sick as they were presumed to be infected by some definite pathogen at the time of study, and hence we may not be able to derive the association between living conditions and respiratory illness. Pregnancy being a compromised condition was also excluded for the same reason.

Given the prevalence of nearly $4 \%$ of prevalence of respiratory diseases globally (Viegi et al., 2005), with 95\% CI and a relative error of $20 \%$, the optimum sample was taken as nearly 400 . A house to house survey was undertaken, after due informed consent of the respondent, by the trained health staff of UHTC including interns and health workers. The study tool was a pretested predesigned respiratory health questionnaire using European Community Respiratory Health Survey (ECRHS II) questionnaire (Burney \& Jarvis, 2002) and International Union against Tuberculosis and Lung Disease (IUATLD) bronchial symptoms questionnaire (Burney et al., 1989), which had also been validated as per Indian scenario (Chowgule, Shetye, Parmar, Bhosale, Khandagale, Phalnitkar, \& Gupta, 1998; Aggarwal et al., 2006; Jindal et al., 2006). The questionnaire was adapted as per the local scenario and translated into Oriya and back translated to ensure quality. Additional questions related to risk- factors such as age, area of the house, overcrowding, annual income, gender, pets and livestock at home, type of house, employment, education, fuel used for cooking, presence of separate kitchen, smoking status and history of tuberculosis were also 
asked.

The data thus collated was analysed using SPSS 16 software. Prevalence rates of self-reported respiratory symptoms and CRI symptoms were defined using descriptive statistics. The association was studied in two step model. In first step Chi-square test was used to study associations between prevalence of CRI and risk-factor variables, such as gender, education, fuel used for cooking, separate kitchen and smoking status. In second step, the significant risk factors variables identified in the first step were adjusted in logistic regression to identify independent associations. The strengths of these associations were measured using odds ratio (OR) with $5 \%$ alpha error and $95 \%$ confidence intervals.

\section{Results}

Table 1 shows that in both genders, above $30 \%$ of population were more than 44 years. Most of the respondents among females were housewives ie $95.7 \%$. Among males $55.3 \%$ were unskilled labourers. Women were less educated.

Table 1. Sociodemographic characteristics of slum population

\begin{tabular}{lll}
\hline \multirow{2}{*}{ Age (years) } & \multicolumn{1}{l}{ Total $(\mathrm{n}=400)$} & Female $(\mathrm{n}=145)$ \\
\cline { 2 - 3 } & Male $(\mathrm{n}=255)$ & $25.2 \%$ \\
\hline $20-24$ & $23.2 \%$ & $23.4 \%$ \\
$25-34$ & $20.8 \%$ & $18.4 \%$ \\
$35-44$ & $20.2 \%$ & $14.5 \%$ \\
$45-54$ & $14.8 \%$ & $\mathbf{1 7 . 4 \%}$ \\
$55-64$ & $\mathbf{2 4 . 0 \%}$ & \\
Occupation & & - \\
Unemployed or retired & $\mathbf{4 0 \%}$ & $\mathbf{9 5 . 7 \%}$ \\
Housewife & - & $2.1 \%$ \\
Unskilled labourer & $55.3 \%$ & $2.2 \%$ \\
Skilled labourer & $4.7 \%$ & \\
Years of education/sc & & $\mathbf{3 4 . 2 \%}$ \\
None & $12.0 \%$ & $\mathbf{1 8 . 9 \%}$ \\
$1-5$ & $18.5 \%$ & $33.7 \%$ \\
$6-10$ & $41.4 \%$ & $11.9 \%$ \\
$11-15$ & $24.5 \%$ & $1.4 \%$ \\
$>15$ & $3.6 \%$ &
\end{tabular}

Table 2. Prevalence of CRI in the sample

\begin{tabular}{llll}
\hline Prevalance of self reporting Symptoms of Dx** & \multicolumn{3}{l}{ Total $(\mathbf{n}=\mathbf{4 0 0})$} \\
\cline { 2 - 4 }$(* *$ multiple responses- three episodes in past year/TB in lifetime $)$ & Male $(\mathrm{n}=255)$ & Female $(\mathrm{n}=145)$ & Cumulative prevalence \\
\hline SOB & $6.2 \%$ & $15.6 \%$ & $10.9 \%$ \\
Wheezing & $9.7 \%$ & $7.8 \%$ & $8.75 \%$ \\
Dry cough & $21.2 \%$ & $25.3 \%$ & $23.25 \%$ \\
Productive cough & $16.9 \%$ & $19.4 \%$ & $18.15 \%$ \\
Severe ARI w hospitalization( past 1 year) & $4.9 \%$ & $0.5 \%$ & $2.7 \%$ \\
Previous Hx of TB & $5.1 \%$ & $7.6 \%$ & $6.35 \%$ \\
\hline
\end{tabular}


Table 2 shows that among the various symptoms asked dry cough was reported high both among males and females $(21.1 \%$ vs $25.3 \%)$ followed by productive cough ( $16.9 \%$ vs $19.4 \%)$. The cumulative prevalence of CRI is calculated by taking average of symptoms reported both in males and females and then calculating the total average which was calculated as $11.7 \%$.

Table 3. Exposure to risk factors

\begin{tabular}{lll}
\hline Risk factors & Total $(\mathrm{n}=400)$ & \\
\cline { 2 - 3 } & Male $(\mathrm{n}=255)$ & Female $(\mathrm{n}=145)$ \\
\hline Ever smokers & $85.7 \%$ & $0.7 \%$ \\
\hline ETS exposure Timings & & \\
none & $22.1 \%$ & $11.3 \%$ \\
adulthood & $40 \%$ & $\mathbf{6 5 . 2} \%$ \\
childhood & 37.9 & $\mathbf{2 3 . 5 \%}$ \\
\hline Cooking & & \\
current & $12.5 \%$ & $\mathbf{9 8 . 2} \%$ \\
past & $35 \%$ & $1.8 \%-$ \\
never & $52.5 \%$ & - \\
\hline
\end{tabular}

Table 3 shows that smoking was far more common in males ie $85.7 \%$ however other risk factors like Environmental Tobacco smoke exposure and cooking due to biomass fuel was far higher in women. Moreover separate kitchens were reported in only $33.7 \%$ households, ventilation or exhaust fan in kitchens in $25.6 \%$, females average age to start cooking was $14-16$ years as against males which was $22-25$ years which was reported as occasional. Kerosene/coal was used in $45 \%$ of households \& wood in $10 \%$ and in most ie $85 \%$ of houses LPG was there but used sparingly

Table 4. Predictors of CRI in the given sample

\begin{tabular}{|c|c|c|c|c|c|}
\hline Correlates & categories & OR & correlates & categories & OR \\
\hline \multirow[t]{3}{*}{ Gender } & male & 1.000 & Use of cooking fuel & Electricity & 1.000 \\
\hline & female & 2.418 & & LPG & 1.032 \\
\hline & & CI-0.824-3.510 & & & CI-.810-1.234 \\
\hline \multirow[t]{10}{*}{ Age } & $20-24$ years & 1:000 & & Kerosene & 6.134 \\
\hline & & & & & CI-.892-54.899 \\
\hline & $25-34$ years & 2.134 & & Coal & 3.214 \\
\hline & & CI $-1.310-2.980$ & & & CI-.687-32.133 \\
\hline & $35-44$ years & 4.172 & & Wood & 1.210 \\
\hline & & CI-3.210-7.230 & & & CI-.939-1.536 \\
\hline & $45-54$ years & 1.456 & & Dung cake & 1.710 \\
\hline & & CI-.987-2.322 & & & CI-.687-4.210 \\
\hline & $55-60$ years & 2.100 & Separate & No cooking & 1.000 \\
\hline & & CI-1.271-2.980 & kitchen & (males\& old) & \\
\hline \multirow[t]{3}{*}{ Overcrowding } & No & 1.000 & & Yes & .876 \\
\hline & & & & & CI-.230-3.210 \\
\hline & Yes & 2.538 & & No & 5.601 \\
\hline
\end{tabular}




\begin{tabular}{|c|c|c|c|c|c|}
\hline & & CI-.693-1.322 & & & CI-2.341-21.420 \\
\hline \multirow[t]{5}{*}{ Ever smoking } & No & 1.000 & Kitchen fan/outlet & $\begin{array}{l}\text { No cooking } \\
\text { (males\& old) }\end{array}$ & 1.000 \\
\hline & Yes & 1.964 & & Yes & 1.020 \\
\hline & & CI-1.334-2.987 & & & CI-891-1.230 \\
\hline & & & & No & 3.420 \\
\hline & & & & & $1.234-3.456$ \\
\hline
\end{tabular}

Table 4 shows the females, age group 35-44 years, overcrowding, use of kerosene for cooking, absence of a separate space for cooking and ventilation in the cooking area are strong predictors of respiratory complaints or symptoms. Contrary to the popular belief that males are more prone to CRI but females are 2.4 times more affected in this population, could be because of their confinement in congested houses and cooking practices.

\section{Discussion and Conclusion}

The study is a dipstick assessment of the vulnerability of populations to Chronic Respiratory Infections that are compounded by their living conditions. CRI has always been associated with men due to the proven association between smoking habits among Indian men and women were always considered safe with regards to these infections. The study also attempts to formulate a community diagnosis for an umbrella group of infections; with the disclaimer that we donot want to draw conclusions regarding the type of respiratory disease ie obstructive or restrictive. Hence the input variables were taken as common recurring respiratory symptoms besides respondents who had diagnosed COPD/asthma or a past history of Tuberculosis.

Very high prevalence of CRI morbidities of $11.7 \%$ was reported in this disease which is comparable to magnitude of chronic obstructive pulmonary disease in our country, especially in rural areas, even when national mortality figures for the same has also been reported to be 11\% (World Health Organization, Regional document, 2011). However, Brashier et al., reported the prevalence of chronic bronchitis to be $16 \%$ in females above the age of 40 years in their study in the slums of Pune city (Brashier, Londhe, Madas, Vincent, \& Salvi, 2012), though the study was undertaken only for women that too in rural areas. This highlights and reaffirms the fact that the health conditions in urban slums are as worse as conditions in rural areas.

This study brings out strongly that women are 2.4 times at greater risk of having respiratory problems. Factors like ETS, lack of separate kitchen or ventilated kitchen and use of kerosene for cooking are also found to be strongly associated with respiratory problems among respondents and could be the reasons for the high prevalence of disease among women. Indoor air pollution from alternate fuel use in all developing countries was estimated to account for about 1.6 million deaths annually in 2004 and about 500,000 in India in 2010, suggesting a serious impact on health (Smith, Mehta, \& Maeusezahl-Feuz, 2004; Wilkinson et al., 2009).

This is a pointer, that in our country we have chronic respiratory diseases on the rise. Our National Programmes which are at present only focussing on smoking restrictions to prevent Respiratory diseases among populations, have to start thinking of this rising population of slums in almost all middle level cities, where the compromised living conditions are potential triggers for CRI.

\section{Competing Interests Statement}

The authors declare that there is no conflict of interests regarding the publication of this paper.

\section{References}

Aggarwal, A. N., Chaudhry, K., Chhabra, S. K., D Souza, G. A., Gupta, D., Jindal, S. K., .. V Vijayan, V. K. (2006). Prevalence and risk factors for bronchial asthma in Indian adults: A multicentre study. Indian Journal of Chest Diseases and Allied Sciences, 48(1), 13.

Brashier, B., Londhe, J., Madas, S., Vincent, V., \& Salvi, S. (2012). Prevalence of self-reported respiratory symptoms, asthma and chronic bronchitis in slum area of a rapidly developing Indian city. Open Journal of Respiratory Diseases, 2(03), 73, 2(3), 73e81. http://dx.doi.org/10.4236/ojrd.2012.23011

Burney, P. G., Laitinen, L. A., Perdrizet, S., Huckauf, H., Tattersfield, A. E., Chinn, S. . . Jones, T. (1989). Validity and repeatability of the IUATLD (1984) Bronchial Symptoms Questionnaire: An international comparison. European respiratory journal, 2(10), 940-945. 
Burney, P., \& Jarvis, D. (2002). ECRHS II (The European Community Respiratory Health Survey II) 2002. Retrieved from www.ecrhs.org

Chowgule, R. V., Shetye, V. M., Parmar, J. R., Bhosale, A. M., Khandagale, M. R., Phalnitkar, S. V., \& Gupta, P. C. (1998). Prevalence of respiratory symptoms, bronchial hyperreactivity, and asthma in a megacity: Results of the European Community Respiratory Health Survey in Mumbai (Bombay). American journal of respiratory and critical care medicine, 158(2), 547-554. http://dx.doi.org/10.1164/ajrccm.158.2.9708064

Jindal, S. K., Aggarwal, A. N., Chaudhry, K., Chhabra, S. K., D Souza, G. A., Gupta, D., . . Vijayan, V. K. (2006). A multicentric study on epidemiology of chronic obstructive pulmonary disease and its relationship with tobacco smoking and environmental tobacco smoke exposure. Indian Journal of Chest Diseases and Allied Sciences, 48(1), 23-27.

Sclar, E. D., Garau, P., \& Carolini, G. (2005). The 21 st century health challenge of slums and cities. The Lancet, 365(9462), 901-903. http://dx.doi.org/10.1016/S0140-6736(05)71049-7.

Smith, K. R., Mehta, S., \& Maeusezahl-Feuz, M. (2004). Indoor air pollution from household use of solid fuels. Comparative quantification of health risks: Global and regional burden of disease attributable to selected major risk factors (Vol. 2, pp. 1435-93).

United Nations Human Settlements Programme: The challenge of slums: Global report on human settlements 2003. (2003). London and Sterling, Earthscan Publications Ltd, 310-312.

United Nations: United Nations Millennium Declaration. Edited by: Assembly TG. 2000, United Nations.

Viegi, G., Maio, S., Pistelli, F., Baldacci, S., \& Carrozzi, L. (2006). Epidemiology of chronic obstructive pulmonary disease: Health effects of air pollution. Respirology, 11(5), 523-532. http://dx.doi.org/10.1111/j.1440-1843.2006.00886.x

Wilkinson, P., Smith, K. R., Davies, M., Adair, H., Armstrong, B. G., Barrett, M., . . Ridley, I. (2009). Public health benefits of strategies to reduce greenhouse-gas emissions: Household energy. The Lancet, 374(9705), 1917-1929. http://dx.doi.org/10.1016/S0140-6736(09)61713-X

World Health Organization, Regional Office for South East Asia. (2011). Non-communicable Diseases in the South-East Asia Region. 2011 Situation and Response. New Delhi, India: WHO Regional Office for SEAR.

\section{Copyrights}

Copyright for this article is retained by the author(s), with first publication rights granted to the journal.

This is an open-access article distributed under the terms and conditions of the Creative Commons Attribution license (http://creativecommons.org/licenses/by/4.0/). 